Supporting Information

\title{
Aggregation-Induced Emission of Water-Soluble Tetraphenylethene Derivatives at Polarized Liquid|Liquid Interfaces
}

\author{
Makoto Nabara, ${ }^{\dagger}$ Sho Yamamoto, ${ }^{\dagger}$ Yoshio Nishiyama, ${ }^{\dagger, \dagger}$ and Hirohisa Nagatani ${ }^{*}, \dagger, \downarrow$ \\ ${ }^{\dagger}$ Division of Material Chemistry, Graduate School of Natural Science and Technology, \\ Kanazawa University, Kakuma, Kanazawa 920-1192, Japan \\ * Faculty of Chemistry, Institute of Science and Engineering, Kanazawa University, Kakuma, \\ Kanazawa 920-1192, Japan
}

*To whom correspondence should be addressed: H. Nagatani

E-mail: nagatani@se.kanazawa-u.ac.jp 


\section{S1. ${ }^{1} \mathrm{H}$ NMR data for tetrakis(4-sulfophenyl)ethene (TPETS).}

The ${ }^{1} \mathrm{H}$ NMR spectra of TPETS lithium salts in $\mathrm{D}_{2} \mathrm{O}$ were recorded on a $400 \mathrm{MHz}$ spectrometer (JEOL JNM-ECS400). Sodium 4,4-dimethyl-4-silapentane-1-sulfonate (DSS) was used as an internal standard.<smiles>COS(=O)(=O)c1ccc(C(=C(c2ccc(S(=O)(=O)[O-])cc2)c2ccc(S(=O)(=O)O)cc2)c2ccc(S(=O)(=O)O)cc2)cc1</smiles>

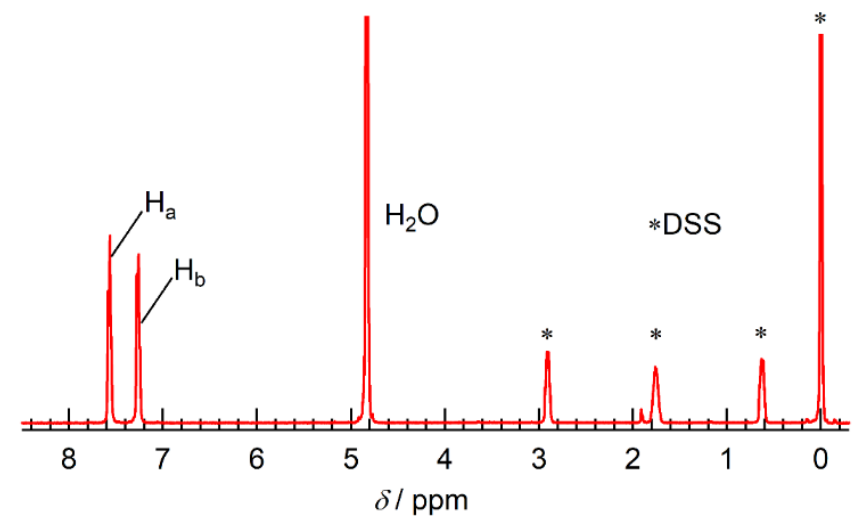

Figure S1. ${ }^{1} \mathrm{H}$ NMR data of TPETS ${ }^{4-}$ in $\mathrm{D}_{2} \mathrm{O}$.

Table S1. Chemical shifts $(\delta)$ and peak area $(S)$ of TPETS ${ }^{4-}$ in $\mathrm{D}_{2} \mathrm{O}$.

\begin{tabular}{cccc}
\hline & $\delta_{\text {ex }} / \mathrm{ppm}$ & $\delta_{\text {ref }} / \mathrm{ppm}$ & $S$ \\
\hline $\mathrm{H}_{\mathrm{a}}$ & $7.57(\mathrm{~d})$ & $7.54(\mathrm{~d})$ & 0.17 \\
$\mathrm{H}_{\mathrm{b}}$ & $7.27(\mathrm{~d})$ & $7.23(\mathrm{~d})$ & 0.17 \\
\hline
\end{tabular}

$\delta_{\text {ex }}$ and $\delta_{\text {ref }}$ are the experimental values in this study and the literature values reported by Ooyama et al. (New J. Chem. 2017, 41, 4747-4749). 


\section{S2. UV-vis absorption and emission spectra of tetraphenylethene (TPE) derivatives.}

(a)

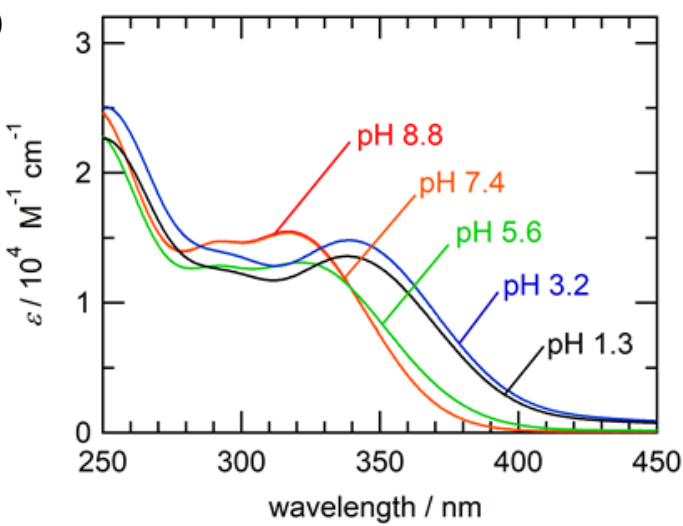

(b)

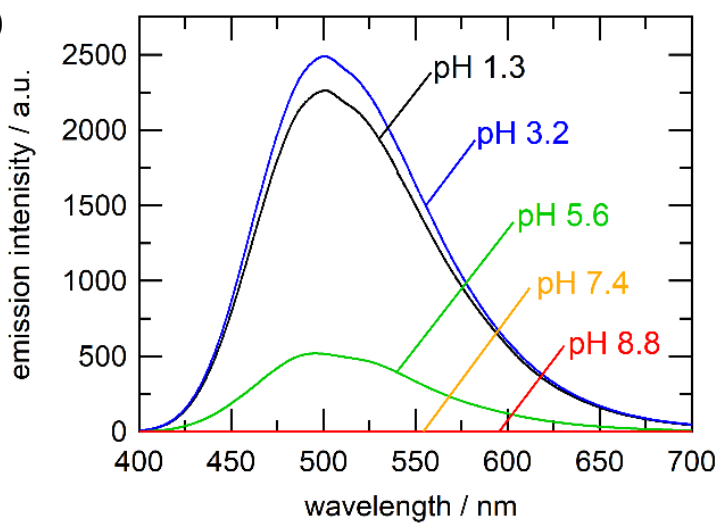

Figure S2. (a) UV-vis absorption and (b) emission spectra of $\mathrm{TPEDC}^{2-}$ in aqueous solutions under various $\mathrm{pH}$ conditions. The excitation wavelength was $376 \mathrm{~nm}$. [TPEDC $\left.{ }^{2-}\right]=2.0 \times 10^{-5}$ $\mathrm{mol} \mathrm{dm}{ }^{-3}$.

(a)

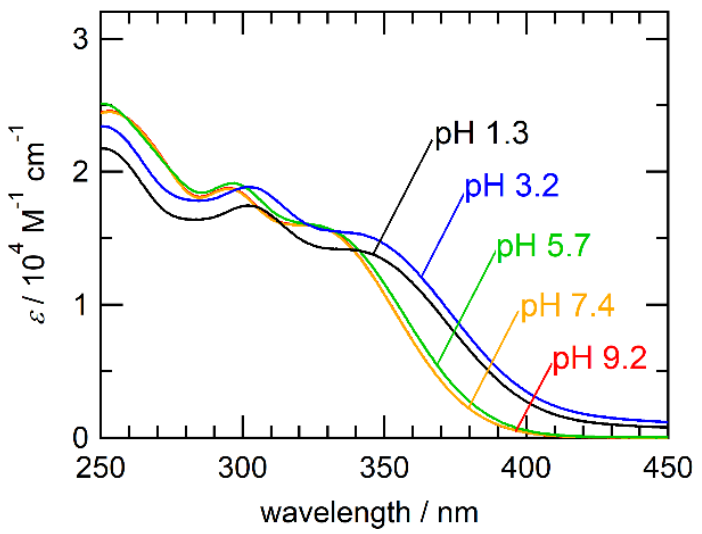

(b)

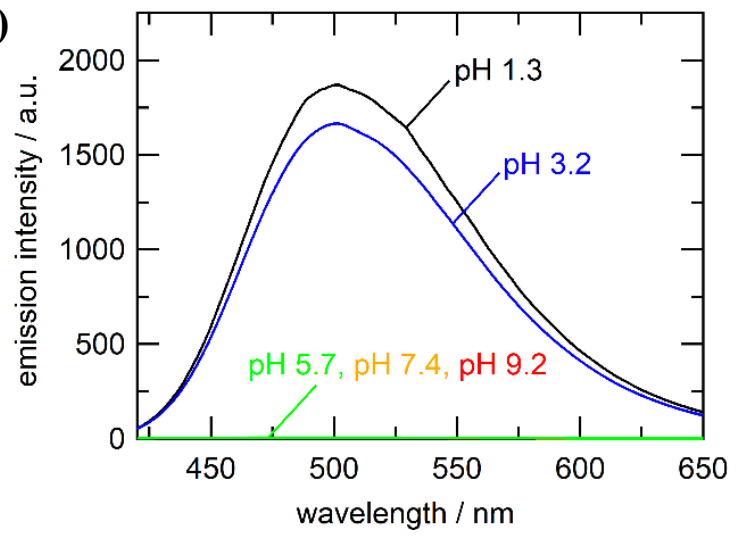

Figure S3. (a) UV-vis absorption and (b) emission spectra of TPETC ${ }^{4-}$ in aqueous solutions under various $\mathrm{pH}$ conditions. The excitation wavelength was $376 \mathrm{~nm}$. [TPETC $\left.{ }^{4-}\right]=2.0 \times 10^{-5}$ mol dm${ }^{-3}$. 
(a)

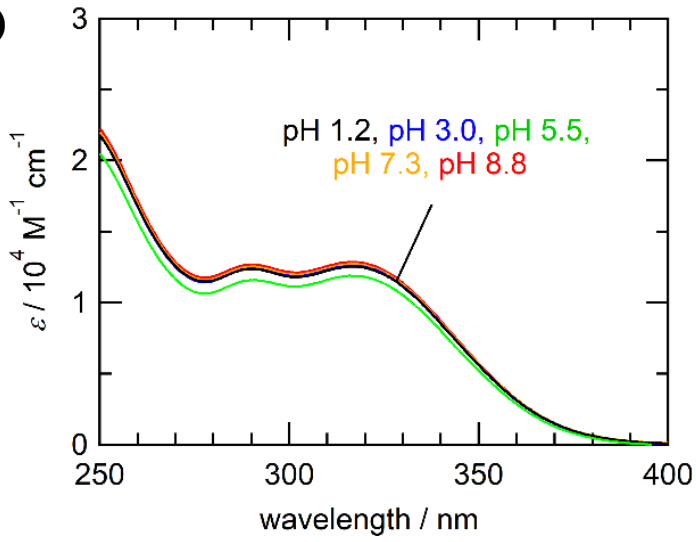

(b)

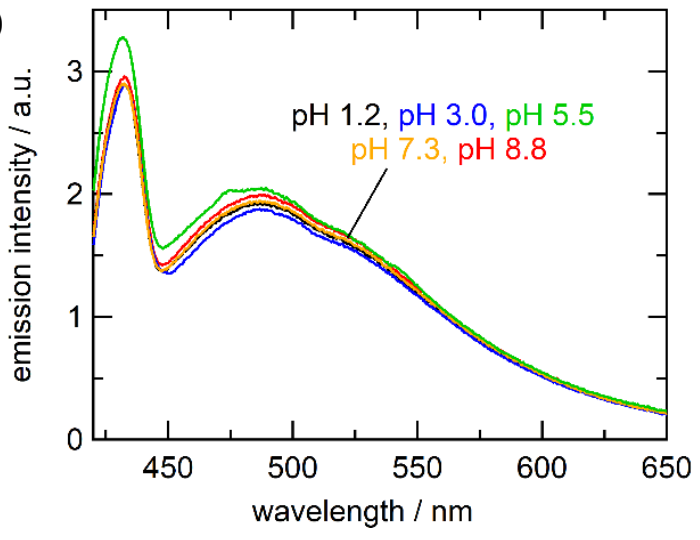

Figure S4. (a) UV-vis absorption and (b) emission spectra of $\mathrm{TPETS}^{4-}$ in aqueous solutions under various $\mathrm{pH}$ conditions. The excitation wavelength was $376 \mathrm{~nm}$. [TPETS $\left.{ }^{4}\right]=2.0 \times 10^{-5}$ mol dm ${ }^{-3}$.

Table S2. Absorption $\left(\lambda_{\mathrm{abs}, \max }\right)$ and emission $\left(\lambda_{\mathrm{em}, \max }\right)$ maxima of TPE derivatives in aqueous solutions

\begin{tabular}{lcccc}
\hline & $\mathrm{pH}$ & $\lambda_{\mathrm{abs}, \max } / \mathrm{nm}$ & $\lambda_{\mathrm{em}, \max } / \mathrm{nm}$ & $I_{\max }$ \\
\hline TPEDC system & 8.8 & 317 & 492 & 3 \\
& 7.4 & 318 & 492 & 3 \\
& 5.6 & 322 & 497 & 518 \\
& 3.2 & 339 & 501 & 2489 \\
& 1.3 & 338 & 501 & 2262 \\
\hline TPETC system & 9.2 & 322 & 488 & 6 \\
& 7.4 & 322 & 488 & 6 \\
& 5.7 & 323 & 490 & 6 \\
& 3.2 & 335 & 501 & 1666 \\
& 1.3 & 338 & 501 & 1870 \\
\hline TPETS system & 8.8 & 317 & 487 & 2 \\
& 7.3 & 317 & 487 & 2 \\
& 5.5 & 317 & 485 & 2 \\
& 3.0 & 317 & 488 & 2 \\
& 1.2 & 317 & 486 & 2 \\
\hline
\end{tabular}




\section{S3. AIE in THF-water mixtures.}

(a)

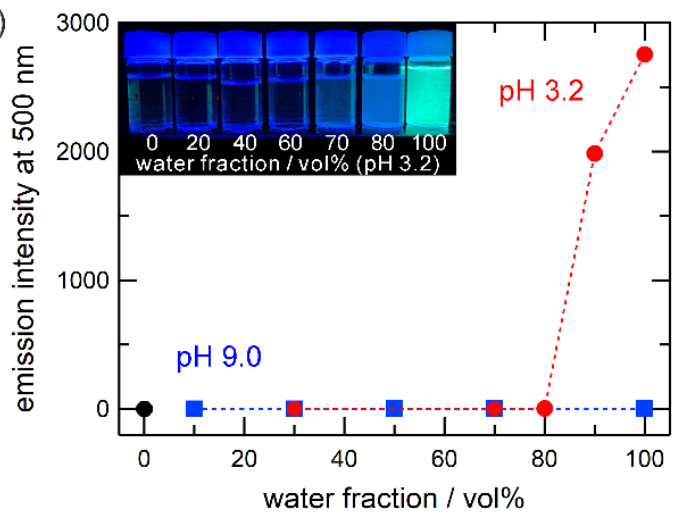

(b)
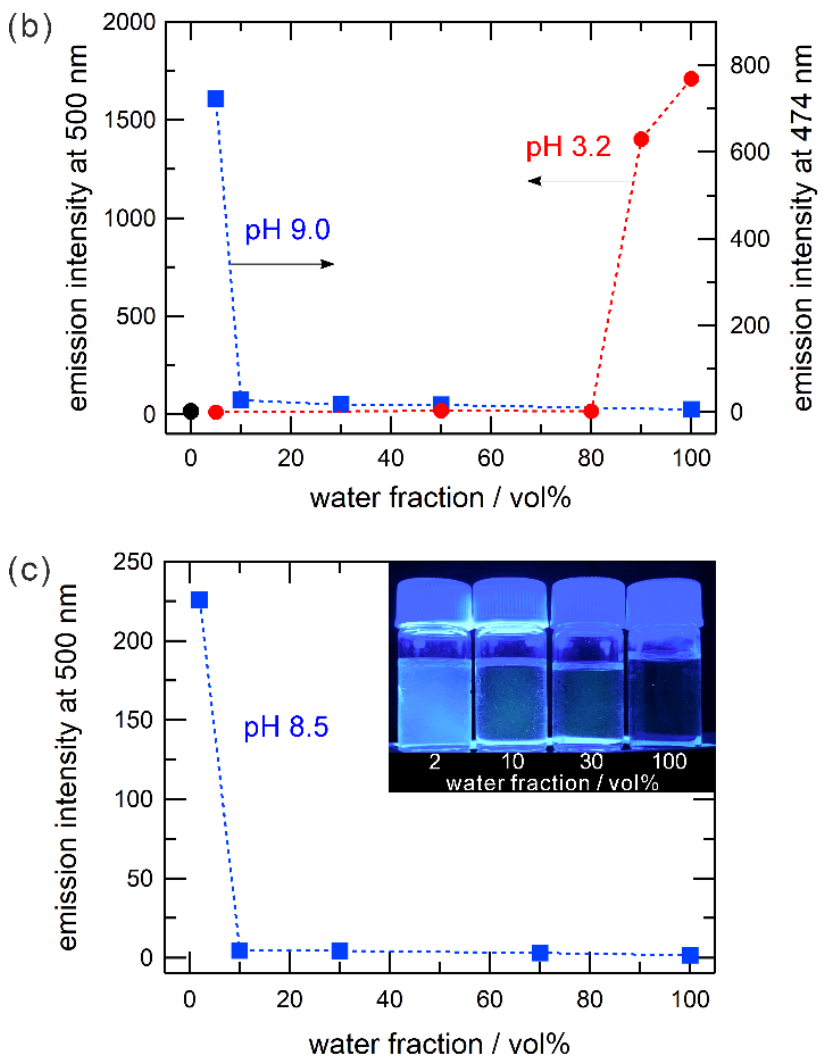

Figure S5. Emission intensities measured for (a) TPEDC, (b) TPETC, and (c) TPETS in waterTHF mixture. The water-THF mixtures with various water fractions were prepared by adding THF to the aqueous solution of TPE derivatives buffered at given $\mathrm{pHs}$. The black circles refer to the emission intensities at $500 \mathrm{~nm}$ for the neutral acid forms in THF, i.e., (a) $\mathrm{H}_{2}$ TPEDC and (b) $\mathrm{H}_{4}$ TPETC. The excitation wavelength was $376 \mathrm{~nm}$. The concentration of the TPE derivatives was $2.0 \times 10^{-5} \mathrm{~mol} \mathrm{dm}^{-3}$. Inset: Typical fluorescence image of TPETS under UV irradiation (365 $\mathrm{nm})$. 
S4. PM-TIRF data for TPETC at the water|DCE interface.
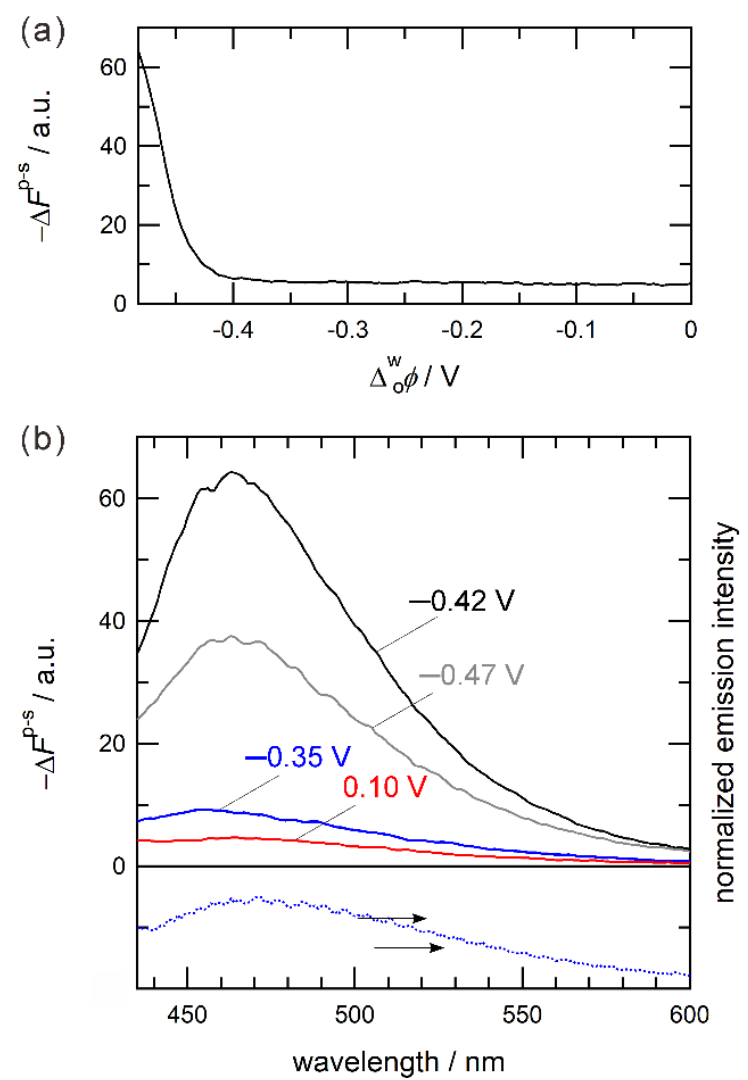

Figure S6. Potential dependences of PM-TIRF intensity at $460 \mathrm{~nm}$ and PM-TIRF spectra for TPETC $^{4-}$ the water|DCE interface. The dotted lines refer to the normalized emission spectra measured in the aqueous (blue) and organic (red) phases. The concentrations of TPETC ${ }^{4-}$ was $5.0 \times 10^{-5} \mathrm{~mol} \mathrm{dm}^{-3}$ in the aqueous phase $(\mathrm{pH} 9.0)$. The linear polarization of the excitation beam at $376 \mathrm{~nm}$ was modulated between $\mathrm{p}$ - and s-polarizations at $13 \mathrm{~Hz}$. 
S5. Ac voltammograms measured at Biomimetic Interfaces.
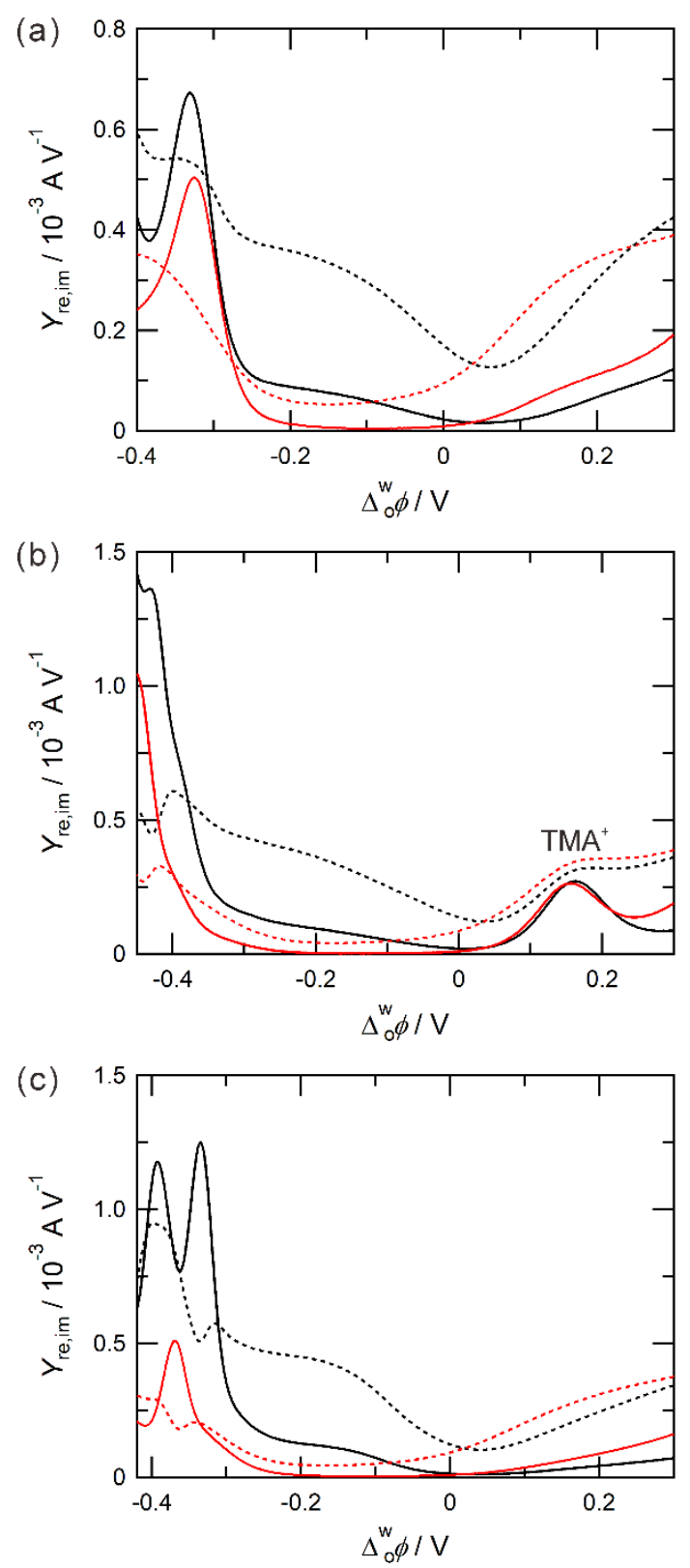

Figure S7. Ac voltammograms measured at the DMPC-adsorbed water|DCE interface for (a) TPEDC $^{2-}$ at $\mathrm{pH} \mathrm{8.7,} \mathrm{(b)} \mathrm{TPETC}^{4-}$ at $\mathrm{pH} \mathrm{8.8,} \mathrm{and} \mathrm{(c)} \mathrm{TPETS}^{4-}$ at $\mathrm{pH}$ 7.0. The solid and dashed lines depict the real $\left(Y_{\mathrm{re}}\right)$ and imaginary $\left(Y_{\mathrm{im}}\right)$ components of the admittance, respectively. The red and black lines refer to the presence and absence of $2.0 \times 10^{-5} \mathrm{~mol} \mathrm{dm}{ }^{-3}$ DMPC in DCE. The concentration of the TPE derivatives was $5.0 \times 10^{-5} \mathrm{~mol} \mathrm{dm}^{-3}$. The ac potential modulation and the linear sweep rate were $10 \mathrm{mV}$ at $7 \mathrm{~Hz}$ and $5 \mathrm{mV} \mathrm{s}^{-1}$, respectively. (b) A $5.0 \times 10^{-5} \mathrm{~mol} \mathrm{dm}^{-3}$ TMACl was added as an internal standard for the $\Delta_{\mathrm{o}}^{\mathrm{w}} \phi$ scale. 